${ }^{6}$ American University of Beirut, Family Medicine, Beirut, Lebanon; ${ }^{7}$ Cochin Hospital, Rheumatology, Paris, France; ${ }^{8}$ Reina Sofia University Hospital / IMIBIC/ University of Cordoba, Rheumatology, Cordoba, Spain; ${ }^{9}$ Cairo University, Rheumatology, Cairo, Egypt; ${ }^{10}$ Kasr Alaini Hospital, Rheumatology, Cairo, Egypt; ${ }^{11}$ Rheumazentrum Ruhrgebiet Herne, Ruhr-University Bochum, Rheumatology, Herne, Germany

Background: In patients with spondyloarthritis (SpA), root joint diseases (RJD), i.e. hip or shoulder involvement, may be associated with a distinct disease phenotype compared to those with other affected joints. The ASAS-PerSpA study (PERipheral involvement in SPondyloArthritis) [1], offers a unique opportunity to study the phenotypes of patients with RJD in a global cohort.

Objectives: Primary objective was to compare the clinical characteristics of $\mathrm{SpA}$ patients with and without RJD. Secondary objectives were to compare the prevalence of RJD across the different SpA subtypes and the different regions of the world, compare the severity of axial disease as well as the disease burden in $\mathrm{SpA}$ patients with and without RJD.

Methods: This is a post-hoc analysis of the ASAS-PerSpA study, which included 4,465 patients with any subtype of SpA (axial SpA (axSpA), peripheral SpA (pSpA), psoriatic arthritis (PsA), inflammatory bowel disease associated SpA (IBD-SpA), reactive arthritis (ReA) and Juvenile SpA (Juv-SpA)) according to the rheumatologist's diagnosis. RJD was defined as a positive answer by the investigator to the following question: "Do you consider that the patient has ever suffered from RJD (e.g. hip, shoulder) related to SpA?" In case of a positive answer, a potential specific treatment (e.g. Total Articular Replacement) was investigated. The patient's characteristics were compared between those with and without RJD involvement, using Chi-2 or Fisher exact test for the categorical variables and t-test for the continuous variables. Two separate multivariable stepwise binary logistic regression analyses were conducted to identify factors associated with the dependent variables "hip involvement" and "shoulder involvement". Results: RJD occurred in 1,503 patients (33.7\%), with more prevalent hip (24.2\%) than shoulder (13.2\%) involvement. The prevalence of RJD as a group was the highest in Juv$\mathrm{SpA}(52.7 \%)$, followed by $\mathrm{pSpA}(44.3 \%)$ and $\operatorname{axSpA}(33.9 \%)$. The highest prevalence of RJD was found in Asia and the lowest in Europe and North America. Among patients with hip involvement, $6.0 \%$ had a history of hip replacement (highest in the Middle East and North Africa and Latin America); among patients with shoulder involvement, $0.8 \%$ had a history of shoulder replacement. Hip had a distinct pattern of associations compared to shoulder involvement (Figure 1). Hip involvement was significantly associated with the SpA main diagnosis (highest in pSpA, lowest in PsA), younger age at first SpA symptom, lower prevalence of family history of psoriasis, positive HLA-B27, occiput-to-wall distance $>0$, and treatment with cs-DMARDs and b-DMARDs. Shoulder involvement was associated with the SpA main diagnosis (highest in Juv-SpA and pSpA, lowest in axSpA), older age at first SpA symptom, higher prevalence of enthesitis, dactylitis, tender joints count, IBD, occiput-to-wall distance>0, EQ5D score and treatment with cs-DMARDs.

Conclusion: Hip involvement was more prevalent than shoulder involvement in patients with $\mathrm{SpA}$, and had a distinct phenotype resembling axial disease whereas shoulder involvement was mostly associated with features of peripheral disease. Hip and shoulder involvement should be analyzed separately in future studies rather than under the RJD entity. REFERENCES:

[1] Lopez-medina, C. et al. Prevalence and Distribution of Peripheral Musculoskeletal Manifestations in Axial Spondyloarthritis, Peripheral Spondyloarthritis and Psoriatic Arthritis: Results of the International, Cross-sectional ASAS-PerSpA Study. RMD Open; 2021;7:e001450.

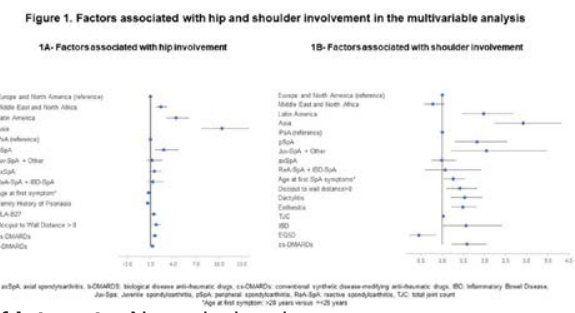

Disclosure of Interests: None declared

DOI: 10.1136/annrheumdis-2021-eular.651

\section{POS0240 GEOGRAPHICAL PREVALENCE OF A FAMILY HISTORY IN PATIENTS WITH AXIAL SPONDYLOARTHRITIS AND ITS ASSOCIATION WITH HLA-B27: DATA FROM THE WORLDWIDE ASAS-PERSPA STUDY}

M. Van Lunteren ${ }^{1}$, A. Boel ${ }^{1}$, C. López-Medina ${ }^{2}$, J. Sieper ${ }^{3,4}$, D. Van der Heijde ${ }^{1}$, F. A. Van Gaalen'1. 'Leiden University Medical Center (LUMC), Rheumatology, Leiden, Netherlands; ${ }^{2}$ Cochin Hospital, Rheumatology, Paris, France $;{ }^{3}$ Charité - Universitätsmedizin Berlin, Campus Benjamin Franklin, Rheumatology, Berlin, Germany; ${ }^{4}$ German Rheumatism Research Centre, Rheumatology, Berlin, Germany

Background: Research has shown that in axial spondyloarthritis (axSpA) patients, the most common form of spondyloarthritis $(\mathrm{SpA})$ in a family history is axSpA. Moreover, the association between a positive family history of spondyloarthritis (PFH) and HLA-B27 carriership is driven by a PFH of axSpA and possibly acute anterior uveitis (AAU), but not by other forms of SpA. However, this research was limited to mostly Western European patients.

Objectives: To investigate the impact of geographical region on family history and its association between HLA-B27 carriership in patients with axSpA around the world. Methods: Data from the Assessment in SpondyloArthritis international Society (ASAS) peripheral involvement in Spondyloarthritis (ASAS-perSpA) study was used. Analyses were restricted to patients with an axSpA diagnosis who had information available on HLA-B27 status and family history. The frequencies of any PFH, as well as a PFH for axSpA, psoriasis, AAU, inflammatory bowel disease (IBD) and reactive arthritis (ReA), were determined per geographical region. Logistic regression models were built to assess the effect of HLA-B27 status on the occurrence of any PFH and each disease in a PFH in the total population and also stratified per geographical region.

Results: In total, 2,048 patients were included from 4 regions: Asia $(n=545)$, Europe \& North America $(n=840)$, Latin America $(n=202)$, and Middle East \& North Africa $(n=461)$. Patients had a median age (IQR) of $40(31-50)$ years, $31 \%$ were female, and had a disease duration of 11 (5-20) years.

A PFH of axSpA was the most common in all geographical regions, regardless of HLA-B27 carriership. A PFH of psoriasis and IBD appeared to be more common in HLA-B27 negative patients, and a PFH of ReA was rare in all patients (figure 1). Univariable logistic regression models showed an association between a PFH and HLA-B27 carriership in the Asian population, but this association does not seem apparent in the other geographical regions (table 1). Contrary, a PFH of axSpA was associated with HLA-B27 carriership in all geographical regions except the Middle East \& North Africa (table 1). An association between HLA-B27 carriership and a PFH of psoriasis was solely present in Middle East \& North Africa ( $\mathrm{OR}=0.4,95 \% \mathrm{Cl}$ 0.2-0.7), and an association with a PFH of IBD was solely present in Europe \& North America (OR=0.5, $95 \% \mathrm{Cl}$ 0.3-0.9). No associations were found for HLA-B27 carriership and a PFH of $\mathrm{AAU}$ and $\mathrm{ReA}$ in any geographical region. There was also no effect modification of geographical region $(p=0.43)$ on the association between HLA-B27 status and a PFH.

Table 1. Univariable associations between HLA-B27 carriership and a positive family history of axSpA patients in the perSpA cohort stratified per geographical region

\begin{tabular}{|c|c|c|c|c|}
\hline & HLA-B27+n=1,609 & HLA-B2 & 9 OR (95\% Cl) & $p$-value \\
\hline \multicolumn{5}{|l|}{ Any positive family history } \\
\hline $\begin{array}{l}\text { Yes } \\
\text { No }\end{array}$ & $\begin{array}{l}631 \\
978\end{array}$ & 149 & $1.26(1.01-1.57)$ & 0.044 \\
\hline Per geographical region & & & & \\
\hline $\begin{array}{l}\text { Asia } \\
\text { Europe \& North America } \\
\text { Latin America }\end{array}$ & $\begin{array}{l}157 / 487 \\
270 / 658 \\
50 / 164\end{array}$ & $\begin{array}{l}11 / 58 \\
67 / 182 \\
9 / 38\end{array}$ & $\begin{array}{l}4.23(2.26-7.91) \\
1.19(0.89-1.61) \\
1.65(0.80-3.39)\end{array}$ & $\begin{array}{l}<0.001 \\
0.241 \\
0.175\end{array}$ \\
\hline \multirow{2}{*}{\multicolumn{5}{|c|}{$\begin{array}{l}\text { Middle East \& North Africa } \\
\text { Positive family history for axSpA }\end{array}$}} \\
\hline & & & & \\
\hline $\begin{array}{l}\text { Yes } \\
\text { No }\end{array}$ & $\begin{array}{l}518 \\
1,087\end{array}$ & $\begin{array}{l}90 \\
348\end{array}$ & $\begin{array}{l}1.84(1.43-2.38) \\
\text { Ref. }\end{array}$ & $<0.001$ \\
\hline $\begin{array}{l}\text { Per geographical region } \\
\text { Asia }\end{array}$ & $144 / 487$ & $11 / 58$ & $4.19(2.24-7.83)$ & $<0.001$ \\
\hline Europe \& North America & $\begin{array}{l}196 / 658 \\
\end{array}$ & $30 / 182$ & $2.09(1.40-3.13)$ & $<0.001$ \\
\hline $\begin{array}{l}\text { Latin America } \\
\text { Middle East \& North Africa }\end{array}$ & $\begin{array}{l}37 / 164 \\
141 / 300\end{array}$ & $\begin{array}{l}3 / 38 \\
46 / 161\end{array}$ & $3.95(1.21-12.89)$ & ) 0.023 \\
\hline
\end{tabular}

B27; OR, odds ratio

Conclusion: Throughout the world, axSpA was the most common form of $\mathrm{SpA}$ in a family history. In all regions except Middle East \& North Africa, a PFH of axSpA was associated with HLA-B27 carriership in axSpA patients. These results suggest that the current expert definition of a PFH of SpA should be revaluated.

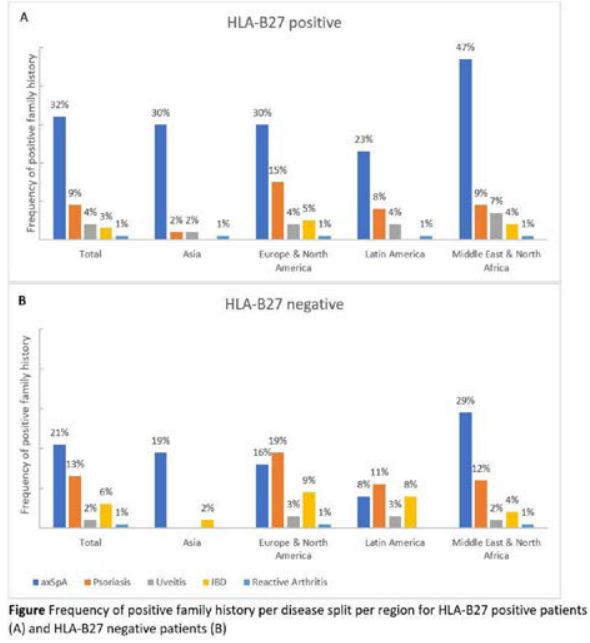

Acknowledgements: We would like to thank all ASAS-perSpA investigators and members of the scientific committee.

Disclosure of Interests: None declared

DOI: 10.1136/annrheumdis-2021-eular.841 